\title{
C4 COMMON TECHNICAL ARCHITECTURE DEVELOPMENT COORDINATION GROUP
}

\section{CONCEPT FOR ESTABLISHMENT WITHIN THE SEDM ${ }^{1}$ PROCESS}

\section{Purpose}

The occurrence of various crises and natural disasters on the Balkans in the past few years strongly supports the need to create a multinational coalition environment for exchange of information among regional partners. For successful implementation of this idea it is necessary to combine information management capabilities of the present and future common regional structures and systems and nationally provided capabilities, i.e., to establish a common technical architecture framework for information management. Another dimension of cooperation in the C4ISR ${ }^{2}$ area is added after September 11, 2001, and the evolving global antiterrorist coalition.

The C4ISR systems studies, conducted recently in most PfP countries in the region, identified similar problems in the field of communications and information systems (CIS) and the plans for their modernization. In order to ensure, in a cost-effective manner, interoperability among the CIS systems of different countries, as well as interoperability with the NATO CIS, the process of modernization should follow a strictly determined technical architecture. On the other hand, a number of present and future SEDM initiatives imply or explicitly require the existence of such common regional architecture. The need to ensure the interoperability among the national and SEDM-common systems calls for a coordination of the process of determination and upgrading of this technical framework. This process is further complicated by the fact that modern communication and information technologies develop extremely fast.

The modernization of the C4ISR infrastructure is a challenge from acquisition and procurement point of view, with important requirements in the area of Research and Development (R\&D) and Education and Training (E\&T), as well as in terms of participation of national defense industries and academic sector in the upcoming and current projects. National content is essential for C4ISR systems, especially regarding software. Thus, a balance between national and international efforts, partnership 
between public, private sector and NGOs, including the academic sector, will be essential.

One of the possible approaches to solve these complex problems is the establishment of a C4 Common Technical Architecture Development Coordination Group ${ }^{3}$ within the SEDM process. The group has to comprise experts in developing C4 systems from the SEDM countries. At regular working meetings the C4 Coordination Group will discuss and propose for approval solutions to problems in the following fields:

1. Definition of technical architecture of technologies, standards, protocols, interfaces, data formats and procedures for data management within which to develop present and future SEDM C4 systems and to insure their functionality in the regional communications and information infrastructure, that is still heterogeneous.

2. Development of a strategy for improvement and further expansion of the shared usage of common systems within SEDM, such as PIMS, CIN, SEESIM.

3. Development of an integral mechanism for analysis and assessment of the C4 systems interoperability - lessons learned from PfP exercises - and creation of a shared database.

4. Coordination, if necessary, on bilateral and multilateral bases of the issues, related to the exchange of information and the interoperability of common projects and systems.

5. Study of possibilities for shared use of the centers, built in different countries, for testing C4 systems interoperability, as well as centers for research and demonstration of advanced technologies. Creation of a proper mechanism for exchange of information on conducted tests and studies of hardware and software.

6. Establishment of a new type of partnership between local industries, Ministries of Defense and international C4ISR companies in the areas of procurement, $\mathrm{R} \& \mathrm{D}, \mathrm{E} \& \mathrm{~T}$, and a strategy for coordinated efforts in restructuring of defense industries, privatization and procurement.

7. Establishment of a new role for NGOs and academic institutions for higher transparency and efficiency in the use of modern IT, especially dual-use, commercial-of-the-shelf, state-of-the-art equipment, and in mechanisms for outsourcing IT services.

\section{Scope \& Functional Areas}

The scope of the C4 Coordination Group will cover, but is not limited to the following functional areas: 
1. User Interface
a. UI Services
b. HCI
c. Graphics \& symbology
d. VTCs

2. Information processing services
a. Operating Systems
b. Internationalization
c. COP/GIS/Terrain visualization
d. CAX and M\&S issues
e. CBT/Online Training/Distance Learning Systems
f. Data Management Services

3. Communications
a. Communications Services
b. Communications Components
c. LAN/WAN
d. External Interfaces

4. Information Interchange
a. Document Data Interchange
b. Graphic Information Interchange
c. Multimedia Interchange
d. Messaging
e. Web based Information distribution \& Applications
f. Tactical Data Link Processing
g. Collaborative Technologies \& Tools

5. Networks (Systems) Management
a. Monitoring of status
b. Addresses management policy
c. Fault recovery
d. Topology controlling

6. CommSec / InfoSec
a. Equipment
b. Software
c. Interfaces
d. Procedures

7. Legal and organizational issues

a. Institution of CIO in SEEDM countries

b. Development of Program Offices, Test-bed Centers, Operators for C4ISR infrastructure in Government 
c. Development of software development centers, maintenance centers, R\&D centers, E\&T centers outside Government around main defense contractors

d. Institutionalization of joint procurement for the region

\section{Structure and Organization}

It is appropriate that the $\mathrm{C} 4$ Coordination Group includes representatives of Ministries of Defense of all countries participating in the SEDM process, as well as in Multinational Peace Force in South East Europe (MPFSEE), while preserving the open format of the organization. The Group shall perform its functions as a militarytechnical expert body supporting the SEDM Coordinating Committee in the field of C4 system development.

It is possible to launch officially the C4 Coordination Group at the Second Regional C4ISR Conference "Systems integration and Program Management" during the HEMUS 2002 defense exhibition in Plovdiv, Bulgaria, in May 2002. This can be truly joint event with participation of Ministries of Defense, industries, academics, and NGOs. A set of demonstration of C4ISR solutions can be arranged during "HEMUS 2002," related to the activity of MPFSEE and using Bulgarian military facilities.

\section{Points of contact:}

Bulgarian Academy of Sciences:

Dr. Velizar Shalamanov, E-mail: bon@mbox.digsys.bg

Ministry of Defense:

LTC Nikolay Petrov, E-mail: petrovn@bg.pims.org

\section{Notes}

1 SEDM - South-eastern Europe Defense Ministerial (process).

2 C4ISR - Command, Control, Communications, Computers, Intelligence, Surveillance and Reconnaissance (systems)

3 Further - "C4 Coordination Group." 